OPEN ACCESS

Edited by:

Alberto Milan,

University of Turin, Italy

Reviewed by:

Corrado Magnino,

Azienda Sanitaria Ospedaliera S.

Croce e Carle Cuneo, Italy

Bertram Pitt,

University of Michigan, United States

${ }^{*}$ Correspondence:

Qiao Weili

wlqiao@xzhmu.edu.cn

tThese authors have contributed equally to this work

Specialty section:

This article was submitted to Hypertension

a section of the journal

Frontiers in Cardiovascular Medicine

Received: 13 February 2021 Accepted: 08 March 2021 Published: 28 April 2021

Citation:

Mprah R, Adzika GK, Gyasi YI, Ndzie

Noah ML, Adu-Amankwaah J, Adekunle AO, Duah M, Wowui Pl and Weili Q (2021) Glutaminolysis: A Driver of Vascular and Cardiac Remodeling in Pulmonary Arterial Hypertension. Front. Cardiovasc. Med. 8:667446. doi: $10.3389 / f C v m .2021 .667446$

\section{Glutaminolysis: A Driver of Vascular and Cardiac Remodeling in Pulmonary Arterial Hypertension}

\author{
Richard Mprah ${ }^{1}$, Gabriel Komla Adzika ${ }^{1 \dagger}$, Yusif I. Gyasi ${ }^{2 \dagger}$, Marie Louise Ndzie Noah ${ }^{1}$, \\ Joseph Adu-Amankwaah ${ }^{1}$, Adebayo O. Adekunle ${ }^{1}$, Maxwell Duah ${ }^{3}$, \\ Prosperl Ivette Wowui ${ }^{4}$ and Qiao Weili ${ }^{1 *}$
}

${ }^{1}$ Department of Physiology, Xuzhou Medical University, Xuzhou, China, ${ }^{2}$ Department of Chemistry \& Biochemistry, Central Michigan University, Mount Pleasant, TX, United States, ${ }^{3}$ Haematology Department, Affiliated Hospital of Xuzhou Medical University, Xuzhou, China, ${ }^{4}$ School of Nursing, Xuzhou Medical University, Xuzhou, China

Pulmonary arterial hypertension (PAH) is a decimating ailment described by chronic precapillary pulmonary hypertension, an elevated mean pulmonary arterial pressure with a normal pulmonary capillary wedge pressure, and a raised pulmonary vascular resistance resulting in increased right ventricular afterload culminating in heart failure and death. Current PAH treatments regulate the vasodilatory/vasoconstrictory balance of pulmonary vessels. However, these treatment options are unable to stop the progression of, or reverse, an already established disease. Recent studies have advanced a metabolic dysregulation, featuring increased glutamine metabolism, as a mechanism driving $\mathrm{PAH}$ progression. Metabolic dysregulation in PAH leads to increased glutaminolysis to produce substrate to meet the high-energy requirement by hyperproliferative and apoptosis-resistant pulmonary vascular cells. This article explores the role of glutamate metabolism in PAH and how it could be targeted as an anti-remodeling therapeutic strategy.

Keywords: pulmonary arterial hypertension, metabolic dysregulation, glutaminolysis, vascular and cardiac remodeling, endothelial dysfunction

\section{INTRODUCTION}

Pulmonary hypertension $(\mathrm{PH})$ entails a group of pulmonary vascular diseases exhibiting a common feature: a high mean pulmonary arterial pressure ( $\geq 25 \mathrm{~mm} \mathrm{Hg}$ at rest). $\mathrm{PH}$ has been, on the etiological basis, categorized into five main groups. Pulmonary arterial hypertension (PAH), classified under group $1 \mathrm{PH}$, is rare but the most decimating type of $\mathrm{PH}$, which affects 15-50 people per million (1). The defining characteristics of PAH constitute abnormal hemodynamics as reviewed by other researchers $(1,2)$, resulting in loss of exercise capacity, breathlessness, right ventricular failure (RVF), and ultimately death. Pathologically, PAH is depicted by inflammation, excessive remodeling of pulmonary blood vessels, obstruction of pulmonary arteries, and increment in pulmonary vascular resistance (PVR), resulting in a pronounced rise in afterload of the right ventricle (RV) $(3,4)$. Consequently, the RV cannot cope with the increase in load, and heart failure (HF) develops (1). Currently, PAH is treated with soluble guanylate cyclase (SGC) stimulators, endothelin receptor antagonists, phosphodiesterase-5 (PDE5) inhibitors, prostacyclin $\left(\mathrm{PGI}_{2}\right)$ analogs, and $\mathrm{PGI}_{2}$ receptor agonists (5-8). 
Even though these drugs have helped improve $\mathrm{PAH}$ patients' quality of life and decrease PVR via acting on the balance between vasoconstriction and vasodilation, they have not been successful at halting the progression, reversing, or curing the disease $(2,4,9,10)$. Progressive pulmonary vascular obstruction leading to increased PVR, which is the mechanism responsible for the HF observed in PAH, may be driven by endothelial cell (EC) dysfunction, cancer-like proliferation, apoptosis-resistant vascular cells, and dysregulation of vascular cell metabolism (3, 11). Recent researches have suggested metabolic reprogramming as a mechanism underlying the hyperproliferative and apoptosisresistant pulmonary vascular cell (PVC) phenotypes associated with vascular remodeling in PAH (12). This review, therefore, elucidates metabolic reprogramming in $\mathrm{PAH}$, with emphasis on how glutamate (Glu) provides a substrate that fuels energy production to drive vascular and cardiac remodeling in $\mathrm{PAH}$, thereby exacerbating the progression of the disease. It also sheds light on the possibility of targeting Glu and its receptors as a therapeutic effector in $\mathrm{PAH}$ treatment.

\section{PATHOBIOLOGY OF PAH}

Remodeling of pulmonary vessels, which often occurs in the pulmonary arterioles, is a distinguishing characteristic of many forms of PH. Pulmonary vascular lesions, the precursor of vascular remodeling, occurring in both human $\mathrm{PAH}$ patients and animal models of $\mathrm{PH}$ occur sequentially. They entail, with some variations, atypical muscularization of medial and distal precapillary arteries, loss of precapillary arteries, inspissation of the pulmonary arteriole wall with eccentric or concentric laminar lesions, neointimal formation, fibrinoid necrosis, and the formation of plexiform lesions $(13,14)$. The remodeling process involves changes in the intima, media, and adventitia walls of the blood vessel. These are due to inflammation, hyperplasia, cellular hypertrophy, metabolic dysregulation, abnormality in cell differentiation and apoptosis, and excessive accumulation and migration of extracellular matrix (ECM) components. Even though the causal pathogeneses of $\mathrm{PAH}$ remain unclear, many research findings have reported numerous contributing and disease-predisposing factors, such as gene mutations, pulmonary endothelial dysfunction, inflammation, and abnormal cell proliferation in the walls of blood vessels $(5,13-15)$. Recently, the novel cancer-like hypothesis (metabolic theory) of $\mathrm{PAH}$ has been postulated and has its origins in fascinating in vitro and in situ observations $(16,17)$. These observations include monoclonal EC expansion observed in idiopathic PAH (iPAH) when compared with ECs reported in lungs of congenital heart disease (CHD) patients (13); evidence of short DNA microsatellite sequence instability within plexiform lesions in iPAH (18); somatic chromosomal abnormalities present in the lungs of PAH patients and cultured cells (19); smooth muscle cells (SMCs) and pulmonary ECs obtained from patients with $\mathrm{PAH}$ when taken from their in vivo environment maintained their aberrant increased-proliferative and apoptosis-resistant phenotype for more extended periods than control cells (1921); and human PVCs from PAH patients exhibited a metabolic dysregulation in situ and in vitro (22-25). Despite this cancer-like concept, there are decisive disparities between the pathogenesis of PAH and carcinogenesis. It is, however, clear that the cancerlike mechanism alone cannot fully elucidate PAH. However, it has uncovered a new field of research regarding the potential use of antiproliferative or cancer drugs in PAH treatment.

\section{METABOLIC BASIS OF PAH}

The metabolic basis of PAH stems from numerous cellular and molecular mechanisms reported in both $\mathrm{PH}$ and cancer that depend on the mitochondria as the focal point of metabolism. As many advances are being made in the area of dysregulations in metabolism in $\mathrm{PAH}, \mathrm{PH} / \mathrm{PAH}$ 's metabolic theory has, as well, widened and evolved farther away from the tenets of the Warburg effect. New additions to the metabolic theory include dysregulation of many pathways, which is also complicated by evidence of different genotypes that alter these responses. Also, the anatomical focal point of metabolic dysregulation has widened. Earlier hypotheses presumed that metabolic dysregulation would, in a logical manner, occur in the pulmonary vasculature. However, increasing proof indicates a deviation of metabolism inside the RV and may be in muscle, indicating paracrine and system outcomes in $\mathrm{PAH}$ progression $(26,27)$. The essence of metabolic dysfunction beyond the vasculature of the lungs has implications in redefining the understanding of metabolism in PAH. The metabolic principles would be necessary for formulating a more cohesive and comprehensive metabolic theory of PAH. Beyond hyperproliferative and antiapoptotic PVC variants, the increasing scope of metabolic dysregulation occasioned the unearthing of other phenotypes altered by metabolic reprogramming in $\mathrm{PAH}$, such as vessel stiffening, fibrosis, and angiogenesis. Besides cardiomyocytes, ECs, and SMCs, where substantial amounts of the early observations of metabolic dysfunction in $\mathrm{PAH}$ cantered, the role of metabolic dysregulation is extending into other types of cells in the vasculature (28). The progressive liaison of metabolic dysregulation and its reprogramming remains a vital question still unanswered. Whether metabolic dysregulation occurs early or late in the progression of $\mathrm{PAH}$ is paramount in comprehending the overwhelming scope of metabolic dysfunction in the disease. There are several organized tiers of mitochondrial dysregulation that results in the various cellular phenotypes of PH. The proliferation of PVCs, ECs, fibroblasts, and SMCs is the defining characteristic of the pathology of $\mathrm{PH}$ (29). The noticed metabolic repositioning toward glycolysis (Warburg effect) in PAH has been related to varied molecular events that bestow the ability to adapt to acute bouts of cellular stress and resist apoptosis. These molecular events include the activation of master regulatory factors, e.g., hypoxia-inducible factor (HIF) and nuclear factor of activated T cells, bioactive metal homeostasis dysregulation, compensatory anaplerosis, decreased mitochondrial reactive oxygen species, internalization and inhibition of oxygen-sensitive voltage-gated potassium $\left(\mathrm{K}^{+}\right)$channels, hyperpolarization of mitochondrial membrane, dysregulation of calcium $\left(\mathrm{Ca}^{2+}\right)$ dynamics, endoplasmic 
reticulum stress, and histone acetylation suppression (29-31). Notwithstanding these short-lived variations, the cell must continue to generate energy and cellular mass at levels enough to meet metabolic requirements, which ideally cannot be solely sustained via enhanced glycolysis and thus require several levels of molecular reprogramming. In the next section, we review how increased Glu uptake provides substrate to meet the high metabolic demands in $\mathrm{PAH}$ as a furtherance of the metabolic basis of PAH.

\section{Implication of Glutamine in PAH}

$\mathrm{PAH}$ is principally propelled by the increased proliferation and migration of vascular cells, resulting in lesion formation that obstructs the pulmonary blood vessels $(32,33)$. This abnormal vascular remodeling response accompanied by fibrosis and vasoconstriction results in increased pressure in pulmonary arteries and, ultimately, RVF and premature death. PAH is initiated by injuries due to exogenous substances such as drugs, infections, toxins, hypoxia, CHD, and several mutations, such as bone morphogenetic protein receptor 2 (BMPR2) gene mutation. Whereas, mitochondrial dysfunction and metabolic reprogramming are known to impart the cellular attributes of $\mathrm{PAH}$, the relevance of glutamine metabolism is now emerging. ECM stiffness, an early pathologic event in $\mathrm{PAH}$, has been noted to stimulate SMCs and pulmonary EC proliferation via the induction of glutaminase (GLS1) by Yes-associated protein 1 (YAP) with PDZ-binding motif (TAZ) (34). GLS1 expression has been observed to increase in pulmonary arterioles of the monocrotaline (MCT)-induced PAH rat model, and glutamine measured in isolated pulmonary ECs decreases, suggestive of both increased glutaminolysis and anaplerotic flux through the Krebs cycle (34). The increased glutaminolysis in PAH also enhances fibrosis by inducing the stability and translation of collagen via $\alpha$-ketoglutarate-mediated mammalian target of rapamycin (mTOR) activation and hydroxylation of proline (35), igniting an aggressive hyperproliferation and arterial stiffening. Pharmacological inhibition of GLS1 activity is reported to disturb this cycle and diminishes arterial remodeling in MCT-induced PAH in rats (36). A similar elevation in GLS1 expression was reported in rhesus macaques monkey with simian-immunodeficiency virus-associated PAH and in the lungs of human immunodeficiency virus-mediated $\mathrm{PAH}$ patients (37). The reconfiguration of Glu metabolism contributes to the maladaptive cardiac remodeling response in $\mathrm{PAH}$, as elevation in glutaminolysis has been observed in the RV of both $\mathrm{PAH}$ patients and MCT-treated rats (36). Recent studies revealed that PAH patients with abnormal BMPR2 functions showed an enormous diminution in glutamine across the transpulmonary gradient compared to control groups (38), alluding that mutations in this receptor may impinge glutamine metabolism. BMPR2 mutant ECs were also reported to depict a hyperproliferative phenotype but are utterly not tolerant of Glu-limiting conditions (39). Yelamanchi et al. reported that this glutamine-addiction is driven downstream from BMPR2 via oxidant damage of the mitochondria, resulting in the development of isoketals that stabilize HIF-1 and inactivate sirtuin-3 (39). Furthermore, scavenging isoketals normalizes glutamine metabolism and prevents PAH in mice with BMPR2 mutation (39). Thus, therapeutic targeting of glutamine metabolism represents a promising approach in treating various forms of PAH.

\section{Metabolic Dysregulation and Increased Glutaminolysis in PAH}

Metabolic dysregulation has been postulated to be liable for the increased proliferation and apoptosis-resistant phenotypes of PVCs concomitant with the vascular remodeling in PAH $(12,25$, 29). This metabolic dysregulation yields a cancer-like glycolytic shift from the normal oxidative phosphorylation (OXPHOS) toward aerobic glycolysis (Warburg effect), elevations in fatty acid oxidation, and glutaminolysis (12, 24, 34, 40). However, a metabolic alteration from OXPHOS to glycolysis alone might not serve as a means of energy (ATP) production for the excessive proliferation of PVCs. Whereas energy generation is less useful for glycolysis per glucose molecule, some earlier studies posited that enough glucose is available in the pulmonary vessels sufficient for ATP production to drive cellular proliferation (31). Nonetheless, a decrease of carbon intermediates, independent of ATP production, conjointly occurs if glucose is jolted away from the tricarboxylic acid (TCA) cycle, hence negatively impacting the carbon substrates employed in the production of nucleotides and proteins (41). Anaplerosis (the process by which carbon intermediates of the TCA cycle are replenished) is crucial in preserving cell mass (nucleotides and proteins), mainly if glycolysis is predominant. One of the pathways for refilling carbon intermediates is through glutaminolysis. Glutaminolysis is an anaplerotic reaction whereby the carbon intermediates of the TCA cycle are refilled, especially when swiftly dividing cells need considerable biomass. Glutaminolysis provides TCA intermediates, which impart fatty and amino acids, and de novo biosynthesis of purine and pyrimidine (42). The elevation in glutaminolysis involves GLS1 upregulation and glutamine uptake by the PAH vasculature, leading to increased production of Glu by the PVCs, driving experimental PH (43).

In similitude to cancer cells, PVCs in $\mathrm{PAH}$ by anaplerosis utilize Glu (in glutaminolysis) to produce $\alpha$-ketoglutarate for the TCA cycle $(34,38,44,45)$ (Figure 1). Dysregulation of glutaminolysis in the heart was observed in right ventricular hypertrophy in animal models of PAH (36). A recent study showed that YAP and transcriptional coactivator with a TAZ are essential for glutaminase upregulation and a resultant glutaminolysis to maintain proliferation and migration in stiff ECM in PAH (34).

\section{Glu Receptor Signaling in PAH}

Glu is an indispensable amino acid that plays a crucial role in signaling as a key excitatory neurotransmitter at the synapses of neurons (46). The functions of Glu are facilitated by the Glu receptors (GluRs), which are categorized into two main groups: ionotropic GluRs (iGluRs) and metabotropic receptors (mGluRs). Many reviews are available on the GluRs in the central nervous system, their functional roles, and how they are implicated in the pathology of neural injury and neuropsychiatric disorders (47-50). However, there is scanty information on its involvement in PAH. GluRs have been characterized based on 


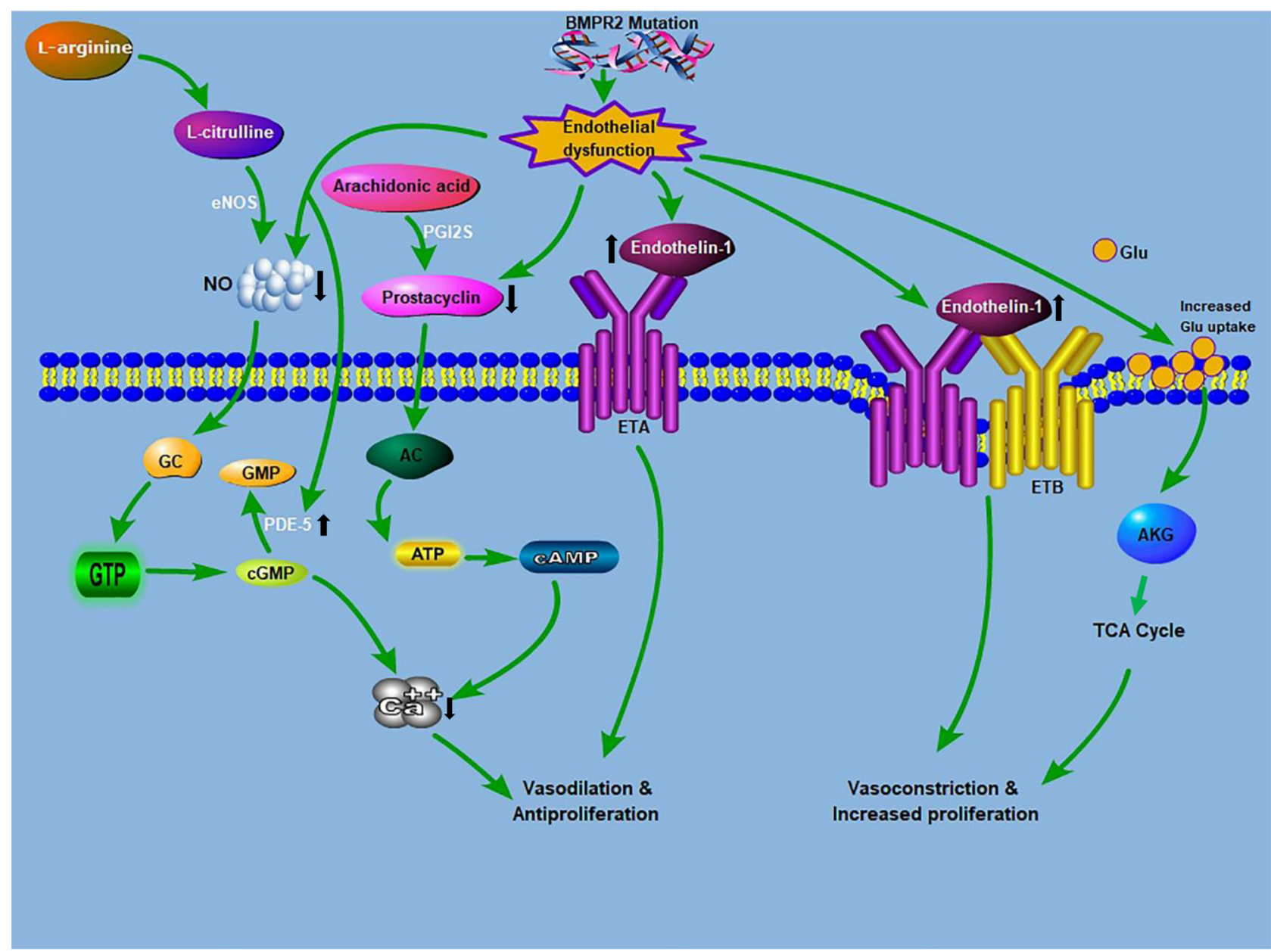

FIGURE 1 | Crosstalk between glutaminolysis and the known PAH pathogenesis: The known PAH pathogenesis: NO, produced from L-arginine, stimulates cGMP production. CGMP causes relaxation and inhibition of vascular SMCs proliferation. PDE5 inhibitors augment the vasodilatory mechanism through the prevention of cGMP deterioration. Prostacyclin from ECs promotes relaxation and inhibition of cell proliferation via a cAMP-dependent mechanism. Endothelin is an effective vasoconstrictor that induces proliferation via $\mathrm{ET}_{\mathrm{A}}$ receptors on $\mathrm{SMCs}$, while stimulating $\mathrm{NO}$ and prostacyclin discharge via endothelial $\mathrm{ET}_{\mathrm{B}}$ receptors. Glutamate provides carbon intermediates ( $\alpha \mathrm{KG}$ ) for the TCA cycle, thereby promoting cellular ATP production, which culminates in increase proliferation and development of antiapoptotic phenotypes. BMPR2 mutation drives endothelial dysfunction, which causes increased endtholin-1 levels and increases glutamate uptake in endothelial cells. AC, adenylyl cyclase; ATP, adenosine triphosphate; AKG, $\alpha$-ketoglutarate; BMPR2, bone morphogenetic protein receptor 2; ETA, endothelin receptor A; ETB, endothelin receptor B; CAMP, cyclic adenosine monophosphate; cGMP, cyclic guanosine monophosphate; eNOS, endothelial nitric oxide synthase; GTP, guanosine triphosphate; GC, guanylyl cyclase; Glu, glutamine; NO, nitric oxide; PDE-5, phosphodiesterase 5; PGI2S, prostacyclin synthase; TCA, tricarboxylic acid.

their sensitivity to specific Glu derivative and their characteristics of the Glu-induced current (Table 2). Structurally, GluR agonists and antagonists are akin to Glu, which allow them to bind the same receptors. A brief overview of GluRs is outlined in Tables 1, 2 because a comprehensive exposition of them has been previously dealt with in detail by others $(47-49,73,74)$.

The iGluRs contain intrinsic cationic channels linked with ligand-binding sites. The iGluR family is organized into three main subtypes: $N$-methyl-D-aspartate (NMDA), $\alpha$-amino-3-hydroxy-5-methyl-4-isoxazole propionic acid, and kainate receptors (73). The membrane channels linked with these receptors depict different electrophysiological and pharmacological properties, including ionic channel selectivity to sodium $\left(\mathrm{Na}^{+}\right), \mathrm{K}^{+}$, and $\mathrm{Ca}^{2+}(73,75)$ (Figure 2). For instance, the NMDA receptors (NMDARs), found in blood vessels, are permeable to $\mathrm{Ca}^{2+}$ ions and have been reported to drive vascular remodeling in $\mathrm{PAH}(43) . \mathrm{Ca}^{2+}$ activates protein kinase $\mathrm{C}$ and its downstream effects (AKT/MAPK pathways), which results in increased cell survival and proliferation, a driver of remodeling in PAH. When NMDARs were blocked, it stopped PAH progression and reversed vascular remodeling (43).

Unlike iGluRs, the mGluRs exact their outcomes either on secondary messengers or ion channels via the stimulation of the guanosine triphosphate-binding proteins and regulate the biosynthesis of distinct intracellular secondary messengers, such as triphosphate inositides $\left(\mathrm{IP}_{3}\right)$, cyclic adenosine monophosphate 
TABLE 1 | Receptor subtypes and their localization.

\begin{tabular}{|c|c|c|c|c|}
\hline Receptor subtypes & Animal & Organ & Cell/tissue type & References \\
\hline $\begin{array}{l}\text { GluR 2/3, Ka2, NMDAR1, } \\
\text { mGluR5, mGluR 2/3, } \\
\text { mGluR1 }\end{array}$ & Rat/monkey & Heart & $\begin{array}{l}\text { Atrium/septum, conducting fibers, cardiomyocytes, } \\
\text { intercalated disc, ganglia cells, nerve fibers, blood vessels }\end{array}$ & $(51-55)$ \\
\hline $\begin{array}{l}\text { GluR2/3, Ka2, NMDAR1, } \\
\text { mGluR 2/3 }\end{array}$ & Rat/monkey & $\begin{array}{l}\text { Ovary and } \\
\text { uterus }\end{array}$ & $\begin{array}{l}\text { Corpus luteum, primordial follicles, theca, granulosa cells, } \\
\text { oocyte, blood vessels, nerve fibers, ectocervix, myometrium, } \\
\text { endometrial glands, epithelium of fallopian tubes }\end{array}$ & $(56)$ \\
\hline $\begin{array}{l}\text { GluR2/3, Ka2, NMDAR1, } \\
\text { mGluR 2/3 }\end{array}$ & Rat & Kidney & $\begin{array}{l}\text { Glomeruli, mesangium, podocytes, juxtaglomerular, } \\
\text { apparatus, tubules }\end{array}$ & $(55,56)$ \\
\hline GluR 2/3, Ka2, NMDAR1 & Rat & Testis & Germinal epithelium, interstitial cells & $(53,56,57)$ \\
\hline GluR2/3, Ka2, NMDAR1 & Rat & Gastrointestinal & $\begin{array}{l}\text { Enteroendocrine cells, parietal cells of the stomach, } \\
\text { pancreatic islets, nerve fibers, ganglia cells, liver }\end{array}$ & $(56,58-62)$ \\
\hline GluR 2/3, Ka 2, NMDAR 1 & Rat & Others & $\begin{array}{l}\text { Lungs, spleen, megakaryocytes, mast cells, inflammatory } \\
\text { cells }\end{array}$ & $(53,56,63-66)$ \\
\hline
\end{tabular}

TABLE 2 | Glutamate receptor protein subunit composition and properties.

\begin{tabular}{|c|c|}
\hline Receptor & Receptor properties \\
\hline \multicolumn{2}{|l|}{ iGluRs } \\
\hline NMDAR & $\begin{array}{l}\text { Heterotetramer; } \uparrow \mathrm{Ca}^{2+} \text { permeability; long } \\
\text { channel open time }(67)\end{array}$ \\
\hline $\begin{array}{l}\text { AMPAR } \\
\text { ( } \alpha \text {-amino-3-hydroxy-5- } \\
\text { methyl-4-isoxazole } \\
\text { propionic acid receptor) }\end{array}$ & $\begin{array}{l}\text { Heterotetramer; } \downarrow \mathrm{Ca}^{2+} \text { permeability low when } \\
\text { edited } \mathrm{GluR}_{2} \text {, somewhat moderate; short } \\
\text { channel open time (68) }\end{array}$ \\
\hline Kainate receptor & $\begin{array}{l}\text { Heterotetramer or homotetramer; } \downarrow \mathrm{Ca}^{2+} \\
\text { permeability; short channel open time }(69-71)\end{array}$ \\
\hline \multicolumn{2}{|l|}{ mGluRs } \\
\hline Group 1 & $\begin{array}{l}\text { Homodimer; signals via phospholipase C; } \\
\text { located postsynaptically (72) }\end{array}$ \\
\hline Group 2 & $\begin{array}{l}\text { Homodimer; located mostly presynaptically; } \\
\text { signals via adenylyl cyclase (AC); agonists and } \\
\text { antagonists mostly distinct from group } 3 \text { (72) }\end{array}$ \\
\hline Group 3 & $\begin{array}{l}\text { Homodimer; mostly located presynaptically; } \\
\text { signals via AC; agonists and antagonists } \\
\text { usually different from group } 2 \text { (72) }\end{array}$ \\
\hline
\end{tabular}

(cAMP), or cyclic guanosine monophosphate $(47,73,75,76)$ (Figure 2). Like iGluRs, the mGluRs are categorized into four groups. Group I, comprising mGluR 1, 5, and 6, induces triphosphoinositides $\left(\mathrm{IP}_{3}\right)$ metabolism and mobilization of intracellular $\mathrm{Ca}^{2+}$ ions (77) (Figure 2). mgluR5 couples with $\mathrm{G}_{\alpha \mathrm{q} / 11}$ to activate $\mathrm{IP}_{3}$ leading to increased release of intracellular $\mathrm{Ca}^{2+}$ and its subsequent signaling mentioned above. Group II (mGluR 2 and 3 ) and group III (mGLuR4, 6-8) are coupled to adenylyl cyclase $(\mathrm{AC})(47,73,75,76,78)$ (Figure 2). ACs are activated by $\mathrm{PGI}_{2}$ to promote vasorelaxation and vasodilation, as well as increase cAMP levels yielding in the activation of protein kinase A (PKA). Activation of PKA resumes various phosphorylating pathways, thereby attenuating the glycolytic shift in $\mathrm{PAH}$. $\mathrm{PGI}_{2}$ also attenuates proliferation of vascular SMCs, inhibition of platelet aggregation, and exertion of antiinflammatory and antithrombotic effects through this same (PKA signaling) pathway (79). As such, both iGluRs and mGluRs may play significant roles in $\mathrm{PAH}$ pathogenesis.

\section{Metabolic Dysregulation and Glutaminolysis as Therapeutic Targets in PAH}

Metabolism is an intricate sequence of molecular events that involve the control of several downstream characteristics of $\mathrm{PH}$. However, it is also a closely regulated process, which means therapeutically controlling metabolic pathways in PAH may be difficult and might yield unintended side effects. Conserved metabolic processes might give room for interventions with the capability of extensive targeting in various tissues and cell types in PAH; nonetheless, the effectiveness of aiming at a conserved pathway can be challenging when considering the local vs. systemic administration of a therapeutic intervention. Likewise, the inherent complexity of metabolism portends a challenge when choosing a target effector, which must, in an ideal condition, have a master regulatory function in reprogramming events. The metabolic disparity also serves as a hurdle in treating potential epigenetic, genetic, and $\mathrm{PH}$-variant differences, which confines innovative therapies to particular populations of patients. Regardless of such challenges, therapeutically targeting metabolism holds an enormous promise to treat early $\mathrm{PAH}$, giving room for the deterrence and/or reversion of pathologic cellular phenotypes (80). Glutaminolysis has become a center of attention in most researches investigating metabolic effectors in $\mathrm{PAH}$ as it has shown promising therapeutic features in some animal models of PAH. For instance, Piao et al. and other researchers reported an increase in glutamine uptake in human patients and animal models of PAH $(36,38,43,81)$. The inhibition of GLS1 in some clinical trials using cancer drugs (NCT02071862) (82), NMDAR using MK-801(43), and YAP using verteporfin (34) has proven to be beneficial in ameliorating PAH progression.

With recourse to the reliance of cancer cells on glutaminolysis, targeted therapies have been developed against glutamine metabolism from glutamine uptake to enzymes that characterize glutaminolytic reactions. For example, the GLS inhibitors 


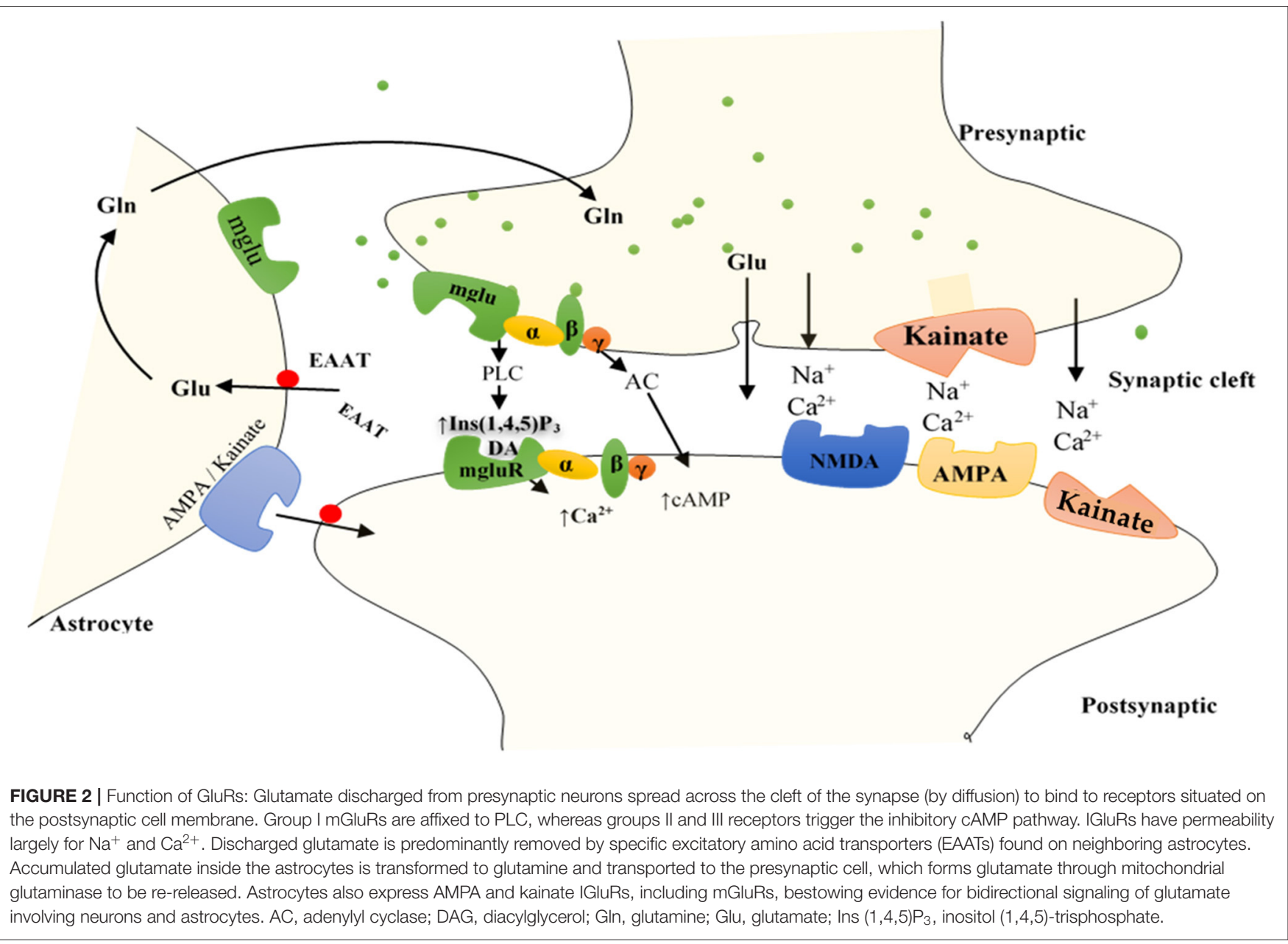

968, bis-2-(5-phenylacetamido-1,2,4-thiadiazol-2-yl)ethyl sulfide 3 (BPTES) and telaglenastat (CB-839) (in phase 1 clinical trials: NCT02071888, NCT02071862, and NCT02771626) have shown promising tumor-suppressive activities in many preclinical animal models (83). In addition to GLS inhibitors, regimens targeting Glu's conversion into $\alpha$-ketoglutarate, such as Glu dehydrogenase inhibitors and aminotransferase inhibitors (e.g., amino-oxyacetic acid), have also been assessed in preclinical models of breast cancer and neuroblastoma (83-86). Also, glutamine analogs such as 6-diazo-5-oxo-L-norleucine (L$\mathrm{DON}$ ), acivicin, and azaserine were reported to nonspecifically target many glutaminolytic enzymes, thereby attenuating Gludependent nucleotide biosynthesis in both preclinical and clinical studies (87). Even though these glutaminase inhibitors and Glu analogs introduced the possibility of targeting Glu addiction in $\mathrm{PAH}$, dose-limiting toxicities associated with their usage, as observed in cancer, must be carefully considered. Despite the dose-limiting toxicities that characterized some glutamine analogs, compounds targeting specific glutaminolytic steps hold enormous therapeutic potential in targeting Glu metabolism in $\mathrm{PAH}$ treatment. For instance, the inhibition of the solute carrier family 1 member 5 (SCL1A5), a known glutamine transporter and an indispensable factor for cell proliferation, by l- $\gamma$-glutamylp-nitroanilide (GPNA) suppressed tumor growth in lung cancer (88). Also, the SCLA5 inhibitors tamoxifen and raloxifene have been reported to restrict glutamine uptake (89). Furthermore, the SLC7A5 inhibitor 2-aminobicyclo(2,2,1)-heptane-2-carboxylic acid $(\mathrm{BCH})$ was reported to inhibit mTOR signaling (90) and hence might be able to attenuate glutaminolysis-induced fibrosis resulting from $\alpha \mathrm{KG}$-mediated mTOR activation and proline hydroxylation in PAH (35).

Finally, the repurposing of presently available therapies that target various metabolic pathways in metabolic disorders such as diabetes might yield beneficial effects in PAH treatment. For example, empagliflozin, a $\mathrm{Na}^{+}$-glucose cotransporter 2 (SGLT2) inhibitor, was reported to lower mortality, reduce RV systolic pressure, and attenuated maladaptive pulmonary remodeling in animal models, thereby preventing PAH progression (91). However, it is not known whether empagliflozin and other SGLT2 inhibitors can reverse an already established PAH, as such further studies would be needed to ascertain the spectrum of their action and usage in PAH therapy. Some drugs that are under development or may be repurposed for PAH treatment have been summarized in Table 3. Also, clinical trials targeting 
TABLE 3 | Potential repurposable drugs for PAH management.

\begin{tabular}{|c|c|c|c|}
\hline Drug & Mechanism of action & Possible effect on PAH & References \\
\hline Pioglitazone & $\begin{array}{l}\text { Activation of peroxisome proliferator-activated } \\
\text { receptor- } \gamma \text { (PPAR } \gamma) \text {; regulates the expression of } \\
\text { various genes tackling insulin resistance, } \\
\text { inflammatory changes, and vascular remodeling }\end{array}$ & $\begin{array}{l}\text { Alleviation of cardiac and vascular remodeling; } \\
\text { improvement in survival }\end{array}$ & (92) \\
\hline Empagliflozin & $\begin{array}{l}\text { Sodium-glucose cotransporter } 2 \text { (SGLT2) inhibitor; } \\
\text { augments excretion of urinary glucose, as well as } \\
\text { reduces cardiovascular events and mortality in type } \\
2 \text { diabetes patients }\end{array}$ & $\begin{array}{l}\text { Improve hemodynamics and survival; reduces } \\
\text { right ventricular hypertrophy and fibrosis; } \\
\text { decreases pulmonary arteriole muscularization } \\
\text { and attenuation of maladaptive cardiac } \\
\text { remodeling }\end{array}$ & $(91,93-95)$ \\
\hline NTP42 & $\begin{array}{l}\text { Novel thromboxane prostanoid receptor (TP) } \\
\text { antagonist (currently under development for } \mathrm{PAH} \\
\text { treatment) }\end{array}$ & $\begin{array}{l}\text { Inhibition of excessive vasoconstriction and } \\
\text { remodeling of pulmonary artery, in situ } \\
\text { thrombosis, inflammation and fibrosis }\end{array}$ & (96) \\
\hline Spironolactone & $\begin{array}{l}\text { Attenuation of impaired vascular reactivity and } \\
\text { endothelial dysfunction due to } \\
\text { hyperaldosteronemia-induced glucose-6-phosphate } \\
\text { dehydrogenase (G6PD) deficiency }\end{array}$ & $\begin{array}{l}\text { Improvement in endothelial dysfunction, } \\
\text { vascular reactivity, NO bioactivity and } \\
\text { vasodilation; must, however, be used along } \\
\text { with drugs with antiremodeling properties for } \\
\text { effectiveness }\end{array}$ & $(97,98)$ \\
\hline $\begin{array}{l}\gamma \text {-Folate binding protein } \\
(\gamma \text {-FBP })\end{array}$ & SCL5A1 inhibitor; prevention of glutamine transport & $\begin{array}{l}\text { Inhibition of glutaminolysis; antiproliferation and } \\
\text { antiremodeling; prevention of PAH progression } \\
\text { and reversal of an already established diseased } \\
\text { condition; suppression of mTOR signaling, } \\
\text { thereby attenuating mTOR-mediated fibrosis }\end{array}$ & (99) \\
\hline $\begin{array}{l}\text { Epigallocatechin gallate } \\
\text { (EGCG) } \\
\text { (NCT02891538) R162 }\end{array}$ & $\begin{array}{l}\text { Glu dehydrogenase inhibitors; prevents the } \\
\text { conversion of glutamate to } \alpha \text { KG; disrupts } \\
\text { anaplerotic utilization of glutamine in the TCA cycle }\end{array}$ & $\begin{array}{l}\text { Suppression/prevention of } \alpha K G \text {-induced } \\
\text { mTOR activation and proline hydroxylation }\end{array}$ & $(86)$ \\
\hline
\end{tabular}

RV dysfunction in PAH has been extensively review by Prisco et al. (100).

\section{CONCLUSION AND FUTURE PERSPECTIVES}

Discussions on the pathophysiology of $\mathrm{PAH}$ over the years majorly centered on the nitric oxide-thromboxane-endothelin 1 $\left(\mathrm{NO}-\mathrm{TXA}_{2}-\mathrm{ET}_{1}\right)$ pathways. However, metabolic dysregulation and reprogramming, resulting in a shift from OXPHOS toward glutaminolysis, have been implicated in $\mathrm{PAH}$ pathogenesis (34). This shift results in Glu addiction, a condition where cells preferentially depend on glutamine as their substrate source for energy production. Glu addiction results in increased glutaminolysis, which triggers the activation of glutaminolytic enzymes. Activation of glutaminolytic enzymes such as GLS drives arterial remodeling in animal models of PAH, whereas increased glutaminolysis induces fibrosis and ignites aggressive hyperproliferation, arterial stiffening, and ECM matrix migration. Also, glutamatergic communication via GluRs

\section{REFERENCES}

1. Torbicki A, Peacock A, Vonk Noordegraaf A, Ghofrani A, Hansmann G, Simonneau G, et al. 2015 ESC/ERS Guidelines for the diagnosis and treatment of pulmonary hypertension: The Joint Task Force for the Diagnosis and Treatment of Pulmonary Hypertension of the European Society of Cardiology (ESC) and the European Respiratory Society (ERS): Endorsed triggers remodeling and obstruction of pulmonary arterioles. Besides, the localization of GluRs such as NMDAR and mgluR5 in the blood vessels and RVs, respectively, alludes to their possible role in $\mathrm{PAH}$ pathogenesis. As such, the targeting of Glu metabolism, glutaminolytic enzymes, and GluRs as therapeutic effectors holds enormous potential in $\mathrm{PAH}$ therapy. The repurposing of certain drugs used in the treatment of diabetes and other metabolic disorders to target the metabolic aberrations in PAH might also yield beneficial results. However, more research needs to be conducted to elucidate their safety for clinical use to avoid unintended side effects that might result from targeting a metabolic pathway(s).

\section{AUTHOR CONTRIBUTIONS}

The review idea was conceived by RM. RM, GA, and YG drafted and wrote the manuscript. With the supervision of QW, RM, GA, YG, MN, AA, JA-A, MD, and PW revised and proofread the manuscript. All authors contributed to the article and approved the submitted version.

2. Galiè N, Humbert M, Vachiery J-L, Gibbs S, Lang I, Torbicki A, et al. 2015 ESC/ERS Guidelines for the diagnosis and treatment of pulmonary hypertension. Eur Res J. (2015) 46:903-975. doi: 10.1183/13993003.0103 $2-2015$ 
3. Schermuly RT, Ghofrani HA, Wilkins MR, Grimminger F. Mechanisms of disease: pulmonary arterial hypertension. Nat Rev Cardiol. (2011) 8:443. doi: $10.1038 /$ nrcardio.2011.87

4. Luna RCP, De Oliveira Y, Lisboa JVC, Chaves TR, de Araújo TA, de Sousa EE, et al. Insights on the epigenetic mechanisms underlying pulmonary arterial hypertension. Braz J Med Biol Res. (2018) 51:e7437. doi: 10.1590/1414-431x20187437

5. Voelkel NF, Gomez-Arroyo J, Abbate A, Bogaard HJ, Nicolls MR. Pathobiology of pulmonary arterial hypertension and right ventricular failure. Eur Res J. (2012) 40:1555-65. doi: 10.1183/09031936.00046612

6. Zhao M, Austin ED, Hemnes AR, Loyd JE, Zhao Z. An evidencebased knowledgebase of pulmonary arterial hypertension to identify genes and pathways relevant to pathogenesis. Mol bioSyst. (2014) 10:732-40. doi: 10.1039/C3MB70496C

7. Lan NSH, Massam BD, Kulkarni SS, Lang CC. Pulmonary arterial hypertension: pathophysiology and treatment. Diseases. (2018) 6:38. doi: $10.3390 /$ diseases 6020038

8. Wilkins MR, Aman J, Harbaum L, Ulrich A, Wharton J, Rhodes CJ. Recent advances in pulmonary arterial hypertension. F1000Res. (2018) 7:1128. doi: 10.12688/f1000research.14984.1

9. Humbert M, Lau EMT, Montani D, Jaïs X, Sitbon O, Simonneau G. Advances in therapeutic interventions for patients with pulmonary arterial hypertension. Circulation. (2014) 130:2189-208. doi: 10.1161/CIRCULATIONAHA.114.006974

10. Sitbon O, Gomberg-Maitland M, Granton J, Lewis MI, Mathai SC, Rainisio $M$, et al. Clinical trial design and new therapies for pulmonary arterial hypertension. Eur Res J. (2019) 53:1801908. doi: 10.1183/13993003.01908-2018

11. Ranchoux B, Antigny F, Rucker-Martin C, Hautefort A, Péchoux C, Bogaard HJ, et al. Endothelial-to-mesenchymal transition in pulmonary hypertension. Circulation. (2015) 131:1006-18. doi: 10.1161/CIRCULATIONAHA.114.008750

12. Paulin R, Michelakis ED. The metabolic theory of pulmonary arterial hypertension. Circ Res. (2014) 115:148-64. doi: 10.1161/CIRCRESAHA.115.301130

13. Guignabert C, Dorfmuller P. Pathology and pathobiology of pulmonary hypertension. Semin Respir Crit Care Med. (2013) 34:551-9. doi: 10.1055/s-0033-1356496

14. Humbert M, Guignabert C, Bonnet S, Dorfmüller P, Klinger JR, Nicolls MR, et al. Pathology and pathobiology of pulmonary hypertension: state of the art and research perspectives. Eur Respir J. (2019) 53:1801887. doi: 10.1183/13993003.01887-2018

15. Rabinovitch M. Molecular pathogenesis of pulmonary arterial hypertension. J Clin Investig. (2012) 122:4306-13. doi: 10.1172/JCI60658

16. Rai PR, Cool CD, King JA, Stevens T, Burns N, Winn RA, et al. (2008). The cancer paradigm of severe pulmonary arterial hypertension. Am J Respir Crit Care Med. 178, 558-564. doi: 10.1164/rccm.200709-1369PP

17. Sakao $S$, Tatsumi K. Vascular remodeling in pulmonary arterial hypertension: multiple cancer-like pathways and possible treatment modalities. Int $J$ Cardiol. (2011) 147:4-12. doi: 10.1016/j.ijcard.2010.07.003

18. Aldred MA, Comhair SA, Varella-Garcia M, Asosingh K, Xu W, Noon GP, et al. Somatic chromosome abnormalities in the lungs of patients with pulmonary arterial hypertension. Am J Respir Crit Care Med. (2010) 182:1153-60. doi: 10.1164/rccm.201003-04910C

19. Tu L, Man FSD, Girerd B, Huertas A, Chaumais M-C, Lecerf F, et al. A critical role for p130Cas in the progression of pulmonary hypertension in humans and rodents. Am J Respir Crit Care Med. (2012) 186:666-76. doi: 10.1164/rccm.201202-0309OC

20. Masri FA, Xu W, Comhair SA, Asosingh K, Koo M, Vasanji A, et al. (2007). Hyperproliferative apoptosis-resistant endothelial cells in idiopathic pulmonary arterial hypertension. Am J Physiol Lung Cell Mol Physiol. 293, L548-54. doi: 10.1152/ajplung.00428.2006

21. Tu L, Dewachter L, Gore B, Fadel E, Dartevelle P, Simonneau G, et al. Autocrine fibroblast growth factor-2 signaling contributes to altered endothelial phenotype in pulmonary hypertension. Am J Respir Cell Mol Biol. (2011) 45:311-22. doi: 10.1165/rcmb.2010-0317OC
22. Xu W, Koeck T, Lara AR, Neumann D, Difilippo FP, Koo M, et al. Alterations of cellular bioenergetics in pulmonary artery endothelial cells. Proc Natl Acad Sci USA. (2007) 104:1342-7. doi: 10.1073/pnas.0605080104

23. Archer SL, Gomberg-Maitland M, Maitland ML, Rich S, Garcia JG, Weir EK. Mitochondrial metabolism, redox signaling, and fusion: a mitochondriaROS-HIF- $1 \alpha-\mathrm{Kv} 1.5 \mathrm{O} 2$-sensing pathway at the intersection of pulmonary hypertension and cancer. Am J Physiol Heart Circ Physiol. (2008) 294:H5708. doi: 10.1152/ajpheart.01324.2007

24. Sutendra G, Bonnet S, Rochefort G, Haromy A, Folmes KD, Lopaschuk GD, et al. Fatty acid oxidation and Malonyl-CoA decarboxylase in the vascular remodeling of pulmonary hypertension. Sci Transl Med. (2010) 2:44ra58. doi: $10.1126 /$ scitranslmed. 3001327

25. Tuder RM, Davis LA, Graham BB. Targeting energetic metabolism a new frontier in the pathogenesis and treatment of pulmonary hypertension. $\mathrm{Am} \mathrm{J}$ Respir Crit Care Med. (2011) 185:260-6. doi: 10.1164/rccm.201108-1536PP

26. Piao L, Fang Y-H, Cadete V, Wietholt C, Urboniene D, Toth P, et al. The inhibition of pyruvate dehydrogenase kinase improves impaired cardiac function and electrical remodeling in two models of right ventricular hypertrophy: resuscitating the hibernating right ventricle. J Mol Med. (2009) 88:47-60. doi: 10.1007/s00109-009-0524-6

27. Malenfant S, Potus F, Fournier F, Breuils-Bonnet S, Pflieger A, Bourassa $S$, et al. Skeletal muscle proteomic signature and metabolic impairment in pulmonary hypertension. J Mol Med. (2014) 93:573-84. doi: 10.1007/s00109-014-1244-0

28. Sawada H, Saito T, Nickel NP, Alastalo TP, Glotzbach JP, Chan R, et al. Reduced BMPR2 expression induces GM-CSF translation and macrophage recruitment in humans and mice to exacerbate pulmonary hypertension. $J$ Exp Med. (2014) 211:263-80. doi: 10.1084/jem.20111741

29. Archer SL, Weir EK, Wilkins MR. Basic science of pulmonary arterial hypertension for clinicians new concepts and experimental therapies. Circulation. (2010) 121:2045-66. doi: 10.1161/CIRCULATIONAHA.108.847707

30. Semenza GL, De Bels D, Corazza F, Kappler M, Balestra C. Oxygen sensing, homeostasis, and disease. New Engl J Med. (2011) 365:1845-6. doi: 10.1056/NEJMra1011165

31. Stenmark KR, Nozik-Grayck E, Gerasimovskaya E, Anwar A, Li M, Riddle S, et al. The adventitia: essential role in pulmonary vascular remodeling. Compr Physiol. (2011) 1:141-61. doi: 10.1002/cphy.c090017

32. Chan SY, Loscalzo J. Pathogenic mechanisms of pulmonary arterial hypertension. J Mol Cell Cardiol. (2008) 44:14-30. doi: 10.1016/j.yjmcc.2007.09.006

33. Rabinovitch M. Molecular pathogenesis of pulmonary arterial hypertension. J Clin Investig. (2008) 118:2372-9. doi: 10.1172/JCI33452

34. Bertero T, Oldham WM, Cottrill KA, Pisano S, Vanderpool RR, Yu Q, et al. Vascular stiffness mechanoactivates YAP/TAZ-dependent glutaminolysis to drive pulmonary hypertension. J Clin Investig. (2016) 126:3313-35. doi: 10.1172/JCI86387

35. Ge J, Cui H, Xie N, Banerjee S, Guo S, Dubey S, et al. Glutaminolysis promotes collagen translation and stability via $\alpha$-Ketoglutarate-mediated mTOR activation and proline hydroxylation. Am J Respir Cell Mol Biol. (2018) 58:378-90. doi: 10.1165/rcmb.2017-0238OC

36. Piao L, Fang Y-H, Parikh K, Ryan JJ, Toth PT, Archer SL. Cardiac glutaminolysis: a maladaptive cancer metabolism pathway in the right ventricle in pulmonary hypertension. J Mol Med. (2013) 91:1185-97. doi: 10.1007/s00109-013-1064-7

37. Durante W. The emerging role of L-glutamine in cardiovascular health and disease. Nutrients. (2019) 11:2092. doi: 10.3390/nu1 1092092

38. Egnatchik RA, Brittain EL, Shah AT, Fares WH, Ford HJ, Monahan K, et al. Dysfunctional BMPR2 signaling drives an abnormal endothelial requirement for glutamine in pulmonary arterial hypertension. Pulm Circ. (2017) 7:18699. doi: $10.1086 / 690236$

39. Yelamanchi SD, Jayaram S, Thomas JK, Gundimeda S, Khan AA, Singhal A, et al. A pathway map of glutamate metabolism. J Cell Commun Signal. (2016) 10:69-75. doi: 10.1007/s12079-015-0315-5

40. Rubin LJ. Metabolic dysfunction in the pathogenesis of pulmonary hypertension. Cell Metab. (2010) 12:313-4. doi: 10.1016/j.cmet.2010.09.006 
41. Frump AL, Lahm T. The basic science of metabolism in pulmonary arterial hypertension. Adv Pulm Hypertens. (2018) 17:95-102. doi: 10.21693/1933-088X-17.3.95

42. Le A, Lane AN, Hamaker M, Bose S, Gouw A, Barbi J, et al. Glucose-independent glutamine metabolism via TCA cycling for proliferation and survival in B cells. Cell Metab. (2012) 15:110-21. doi: 10.1016/j.cmet.2011.12.009

43. Dumas SJ, Bru-Mercier G, Courboulin A, Quatredeniers M, Rücker-Martin C, Antigny F, et al. NMDA-type glutamate receptor activation promotes vascular remodeling and pulmonary arterial hypertension. Circulation. (2018) 137:2371-89. doi: 10.1161/CIRCULATIONAHA.117.029930

44. Kaadige MR, Looper RE, Kamalanaadhan S, Ayer DE. Glutamine-dependent anapleurosis dictates glucose uptake and cell growth by regulating MondoA transcriptional activity. Proc Natl Acad Sci USA. (2009) 106:14878-83. doi: 10.1073/pnas.0901221106

45. Bertero T, Cottrill KA, Lu Y, Haeger CM, Dieffenbach P, Annis S, et al. Matrix remodeling promotes pulmonary hypertension through feedback mechanoactivation of the YAP/TAZ-miR-130/301 circuit. Cell Rep. (2015) 13:1016-32. doi: 10.1016/j.celrep.2015.09.049

46. Nedergaard M, Takano T, Hansen AJ. Beyond the role of glutamate as a neurotransmitter. Nat Rev Neurosci. (2002) 3:748. doi: 10.1038/nrn916

47. Gill S, Goldstein T, Situ D, Zabka TS, Gulland FMD, Mueller RW. Cloning and characterization of glutamate receptors in Californian sea lions (Zalophus californianus). Marine Drugs. (2010) 8:1637-49. doi: $10.3390 / \mathrm{md} 8051637$

48. Filippini A, Bonini D, La Via L, Barbon A. The good and the bad of glutamate receptor RNA editing. Mol Neurobiol. (2017) 54:6795-805. doi: $10.1007 / \mathrm{s} 12035-016-0201-\mathrm{z}$

49. Bouvier G, Larsen RS, Rodríguez-Moreno A, Paulsen O, Sjöström PJ. Towards resolving the presynaptic NMDA receptor debate. Curr Opin Neurobiol. (2018) 51:1-7. doi: 10.1016/j.conb.2017.12.020

50. O'brien J, Bloomfield SA. Plasticity of retinal gap junctions: roles in synaptic physiology and disease. Ann Rev Vis Sci. (2018) 4:79-100. doi: 10.1146/annurev-vision-091517-034133

51. Moroni F, Luzzi S, Franchi-Micheli S, Zilletti L. The presence of N-methyl-daspartate-type receptors for glutamic acid in the guinea pig myenteric plexus. Neurosci Lett. (1986) 68:57-62. doi: 10.1016/0304-3940(86)90229-6

52. Purcell WM, Doyle KM, Westgate C, Atterwill CK. Characterisation of a functional polyamine site on rat mast cells: association with a NMDA receptor macrocomplex. J Neuroimmunol. (1996) 65:49-53. doi: 10.1016/0165-5728(95)00182-4

53. Gill SS, Pulido OM, Mueller RW, Mcguire PF. Molecular and immunochemical characterization of the ionotropic glutamate receptors in the rat heart. Brain Res Bull. (1998) 46:429-34. doi: 10.1016/S0361-9230(98)00012-4

54. Gill SS, Pulido OM, Mueller RW, Mcguire PF. Immunochemical localization of the metabotropic glutamate receptors in the rat heart. Brain Res Bull. (1999) 48:143-6. doi: 10.1016/S0361-9230(98)00154-3

55. O'connell DP, Aherne AM, Lane E, Felder RA, Carey RM. Detection of dopamine receptor D1Asubtype-specific mRNA in rat kidney by in situ amplification. Am J Physiol Renal Physiol. (1998) 274:F232-41. doi: 10.1152/ajprenal.1998.274.1.F232

56. Glazner GW, Chan SL, Lu C, Mattson MP. Caspase-mediated degradation of AMPA receptor subunits: a mechanism for preventing excitotoxic necrosis and ensuring apoptosis. J Neurosci. (2000) 20:3641. doi: 10.1523/JNEUROSCI.20-10-03641.2000

57. Lindström P, Ohlsson L. Effect of N-methyl-D,L-aspartate on isolated rat somatotrophs. Endocrinology. (1992) 131:1903-7. doi: 10.1210/endo.131.4.1396334

58. Bertrand G, Gross R, Puech R, Loubatières-Mariani MM, Bockaert J. Evidence for a glutamate receptor of the AMPA subtype which mediates insulin release from rat perfused pancreas. Br J Pharmacol. (1992) 106:354-9. doi: 10.1111/j.1476-5381.1992.tb14340.x

59. Bertrand G, Gross R, Puech R, Loubatières-Mariani M-M, Bockaert J. Glutamate stimulates glucagon secretion via an excitatory amino acid receptor of the AMPA subtype in rat pancreas. Eur J Pharmacol. (1993) 237:45-50. doi: 10.1016/0014-2999(93)90091-U
60. Burns GA, Stephens KE, Benson JA. Expression of mRNA for the N-methyld-aspartate (NMDAR1) receptor by the enteric neurons of the rat. Neurosci Lett. (1994) 170:87-90. doi: 10.1016/0304-3940(94)90245-3

61. Inagaki $\mathrm{N}$, Kuromi $\mathrm{H}$, Gonoi $\mathrm{T}$, Okamoto $\mathrm{Y}$, Ishida $\mathrm{H}$, Seino $\mathrm{Y}$, et al. Expression and role of ionotropic glutamate receptors in pancreatic islet cells. FASEB J. (1995) 9:686-91. doi: 10.1096/fasebj.9.8.7768362

62. Lipton SA, Gendelman HE. Dementia associated with the acquired immunodeficiency syndrome. New Engl J Med. (1995) 332:934-40. doi: 10.1056/NEJM199504063321407

63. Price MT, Olney JW, Lowry OH, Buchsbaum S. Uptake of exogenous glutamate and aspartate by circumventricular organs but not other regions of brain. J Neurochem. (1981) 36:1774-80. doi: 10.1111/j.1471-4159.1981.tb00430.x

64. Storto M, De Grazia U, Battaglia G, Felli MP, Maroder M, Gulino A, et al. Expression of metabotropic glutamate receptors in murine thymocytes and thymic stromal cells. J Neuroimmunol. (2000) 109:112-20. doi: 10.1016/S0165-5728(00)00269-1

65. Lombardi G, Dianzani C, Miglio G, Canonico PL, Fantozzi R. Characterization of ionotropic glutamate receptors in human lymphocytes. Br J Pharmacol. (2001) 133:936-44. doi: 10.1038/sj.bjp.0704134

66. Said SI. Glutamate toxicity in lung and airway disease. In: Gill S, Pulido O, editors. Glutamate Receptors in Peripheral Tissue: Excitatory Transmission Outside the CNS. Boston, MA: Springer US (2005). p. 191-6.

67. Liu J, Chang L, Song Y, Li H, Wu Y. The role of NMDA receptors in Alzheimer's disease. Front Neurosci. (2019) 13:43. doi: $10.3389 /$ fnins. 2019.00043

68. Robertson SJ, Burnashev N, Edwards FA. Ca2+ permeability and kinetics of glutamate receptors in rat medial habenula neurones: implications for purinergic transmission in this nucleus. J Physiol. (1999) 518:539-49. doi: 10.1111/j.1469-7793.1999.0539p.x

69. Matute C. Therapeutic potential of kainate receptors. CNS Neurosci Ther. (2010) 17:661-9. doi: 10.1111/j.1755-5949.2010.00204.x

70. Doumazane E, Scholler P, Zwier JM, Trinquet E, Rondard P, Pin JP. A new approach to analyze cell surface protein complexes reveals specific heterodimeric metabotropic glutamate receptors. FASEB J. (2011) 25:66-77. doi: $10.1096 /$ fj. $10-163147$

71. Lerma J, Marques J. Kainate receptors in health and disease. Neuron. (2013) 80:292-311. doi: 10.1016/j.neuron.2013.09.045

72. Niswender CM, Conn PJ. Metabotropic glutamate receptors: physiology, pharmacology, and disease. Ann Rev Pharmacol Toxicol. (2010) 50:295-322. doi: 10.1146/annurev.pharmtox.011008.145533

73. Mayer ML. Glutamate receptor ion channels. Curr Opin Neurobiol. (2005) 15:282-8. doi: 10.1016/j.conb.2005.05.004

74. Bouvier G, Bidoret C, Casado M, Paoletti P. Presynaptic NMDA receptors: roles and rules. Neuroscience. (2015) 311:322-40. doi: 10.1016/j.neuroscience.2015.10.033

75. Platt SR. The role of glutamate in central nervous system health and disease - A review. Vet J. (2007) 173:278-86. doi: 10.1016/j.tvjl.2005.11.007

76. Maksymetz J, Moran S, Conn P. Targeting metabotropic glutamate receptors for novel treatments of schizophrenia. Mol Brain. (2017) 10:15. doi: 10.1186/s13041-017-0293-z

77. Litim N, Morissette M, Di Paolo T. Metabotropic glutamate receptors as therapeutic targets in Parkinson's disease: an update from the last 5 years of research. Neuropharmacology. (2017) 115:166-79. doi: 10.1016/j.neuropharm.2016.03.036

78. Simeone TA, Sanchez RM, Rho JM. Molecular biology and ontogeny of glutamate receptors in the mammalian central nervous system. J Child Neurol. (2004) 19:343-60. doi: 10.1177/088307380401900507

79. Lai Y-C, Potoka KC, Champion HC, Mora AL, Gladwin MT. Pulmonary arterial hypertension: the clinical syndrome. Circ Res. (2014) 115:115-30. doi: 10.1161/CIRCRESAHA.115.301146

80. Hensley MK, Levine A, Gladwin MT, Lai Y-C. Emerging therapeutics in pulmonary hypertension. Am J Physiol Lung Cell Mol Physiol. (2018) 314:L769-81. doi: 10.1152/ajplung.00259.2017

81. Ryan JJ, Archer SL. Emerging concepts in the molecular basis of pulmonary arterial hypertension: part I: metabolic plasticity and mitochondrial dynamics in the pulmonary circulation and right ventricle 
in pulmonary arterial hypertension. Circulation. (2015) 131:1691-702. doi: 10.1161/CIRCULATIONAHA.114.006979

82. Gross MI, Demo SD, Dennison JB, Chen L, Chernov-Rogan T, Goyal B, et al. Antitumor activity of the glutaminase inhibitor CB-839 in triple-negative breast cancer. Mol Cancer Ther. (2014) 13:890-901. doi: 10.1158/1535-7163.MCT-13-0870

83. Jin L, Alesi GN, Kang S. Glutaminolysis as a target for cancer therapy. Oncogene. (2016) 35:3619-25. doi: 10.1038/onc.2015.447

84. Li M, Allen A, Smith TJ. High throughput screening reveals several new classes of glutamate dehydrogenase inhibitors. Biochemistry. (2007) 46:15089-102. doi: 10.1021/bi7018783

85. Qing G, Li B, Vu A, Skuli N, Walton Z, Liu X, et al. ATF4 regulates MYCmediated neuroblastoma cell death upon glutamine deprivation. Cancer Cell. (2012) 22:631-44. doi: 10.1016/j.ccr.2012.09.021

86. Korangath P, Teo WW, Sadik H, Han L, Mori N, Huijts CM, et al. Targeting glutamine metabolism in breast cancer with aminooxyacetate. Clin Cancer Res. (2015) 21:3263-73. doi: 10.1158/1078-0432.C.C.R.-14-1200

87. Ahluwalia GS, Grem JL, Hao Z, Cooney DA. Metabolism and action of amino acid analog anti-cancer agents. Pharmacol Ther. (1990) 46:243-71. doi: 10.1016/0163-7258(90)90094-I

88. Hassanein M, Qian J, Hoeksema MD, Wang J, Jacobovitz M, Ji X, et al. Targeting SLC1a5-mediated glutamine dependence in non-small cell lung cancer. Cancer Cell Biol. (2015) 137:1587-97. doi: 10.1002/ijc.29535

89. Todorova VK, Kaufmann Y, Luo S, Klimberg VS. Tamoxifen and raloxifene suppress the proliferation of estrogen receptor-negative cells through inhibition of glutamine uptake. Cancer Chemother Pharmacol. (2011) 67:285-91. doi: 10.1007/s00280-010-1316-y

90. Nicklin P, Bergman P, Zhang B, Triantafellow E, Wang H, Nyfeler B, et al. Bidirectional transport of amino acids regulates mTOR and autophagy. Cell. (2009) 136:521-34. doi: 10.1016/j.cell.2008.11.044

91. Chowdhury B, Luu AZ, Luu VZ, Kabir MG, Pan Y, Teoh H, et al. The SGLT2 inhibitor empagliflozin reduces mortality and prevents progression in experimental pulmonary hypertension. Biochem Biophys Res Commun. (2020) 524:50-6. doi: 10.1016/j.bbrc.2020.01.015

92. Behringer A, Trappiel M, Berghausen EM, Ten Freyhaus H, Wellnhofer E, Odenthal $\mathrm{M}$, et al. Pioglitazone alleviates cardiac and vascular remodelling and improves survival in monocrotaline induced pulmonary arterial hypertension. Naunyn Schmiedebergs Arch Pharmacol. (2016) 389:369-79. doi: $10.1007 / \mathrm{s} 00210-015-1205-3$

93. Michel MC, Mayoux E, Vallon V. A comprehensive review of the pharmacodynamics of the SGLT2 inhibitorempagliflozin in animals and humans. Naunyn Schmiedebergs Arch Pharmacol. (2015) 388:801-16. doi: 10.1007/s00210-015-1134-1

94. Lee H-C, Shiou Y-L, Jhuo S-J, Chang C-Y, Liu P-L, Jhuang W$\mathrm{J}$, et al. The sodium-glucose co-transporter 2 inhibitor empagliflozin attenuates cardiac fibrosis and improves ventricular hemodynamics in hypertensive heart failure rats. Cardiovasc Diabetol. (2019) 18:45-45. doi: 10.1186/s12933-019-0849-6

95. Herat LY, Matthews VB, Magno AL, Kiuchi MG, Carnagarin R, Schlaich MP. An evaluation of empagliflozin and it's applicability to hypertension as a therapeutic option. Exp Opin Pharmacother. (2020) 21:1157-66. doi: 10.1080/14656566.2020.1751815

96. Mulvaney EP, Reid HM, Bialesova L, Bouchard A, Salvail D, Kinsella BT. NTP42, a novel antagonist of the thromboxane receptor, attenuates experimentally induced pulmonary arterial hypertension. BMC Pulm Med. (2020) 20:85. doi: 10.1186/s12890-020-1113-2

97. Farquharson CJ, Struthers AD. Spironolactone increases nitric oxide bioactivity, improves endothelial vasodilator dysfunction, and suppresses vascular angiotensin I/angiotensin II conversion in patients with chronic heart failure. Circulation. (2000) 101:594-7. doi: 10.1161/01.CIR.101. 6.594

98. Leopold JA, Dam A, Maron BA, Scribner AW, Liao R, Handy DE, et al. Aldosterone impairs vascular reactivity by decreasing glucose-6phosphate dehydrogenase activity. Nat Med. (2007) 13:189-97. doi: 10.1038/ nm1545

99. Choi Y-K, Park K-G. Targeting glutamine metabolism for cancer treatment. Biomol Ther. (2018) 26:19-28. doi: 10.4062/biomolther.2017.178

100. Prisco SZ, Thenappan T, Prins KW. Treatment targets for right ventricular dysfunction in pulmonary arterial hypertension. JACC Basic Transl Sci. (2020) 5:1244-60. doi: 10.1016/j.jacbts.2020.07.011

Conflict of Interest: The authors declare that the research was conducted in the absence of any commercial or financial relationships that could be construed as a potential conflict of interest.

Copyright $\odot 2021$ Mprah, Adzika, Gyasi, Ndzie Noah, Adu-Amankwaah, Adekunle, Duah, Wowui and Weili. This is an open-access article distributed under the terms of the Creative Commons Attribution License (CC BY). The use, distribution or reproduction in other forums is permitted, provided the original author(s) and the copyright owner(s) are credited and that the original publication in this journal is cited, in accordance with accepted academic practice. No use, distribution or reproduction is permitted which does not comply with these terms. 